\title{
Comparing the effects of intraoperative information delivery via electronic patient tracking system and mobile phone on stress and coping ability among the family members of patients under coronary artery bypass graft surgery
}

\author{
Afsaneh Fazel $^{\mathbb{D}}$, Kobra Noorian ${ }^{* \mathbb{D}}$, Fereshteh Aein ${ }^{\mathbb{D}}$, Fatemeh Deris ${ }^{(\mathbb{D}}$ \\ Community-based Nursing Midwifery Research Center, Nursing and Midwifery School, Shahrekord University of Medical \\ Sciences, Shahrekord, Iran
}

\begin{abstract}
Background and aims: Coronary artery bypass graft (CABG) surgery is associated with high levels of stress for patients' family members. Information delivery to family members is a strategy with potential positive effects on their stress. The aim of the present study was to compare the effects of intraoperative information delivery via electronic patient tracking system (EPTS) and mobile-based communication (MBC) on stress and coping ability among the family members of patients under CABG surgery.

Methods: This clinical trial was conducted on 80 family members of patients under CABG surgery. Participants were randomly allocated to an EPTS and an MBC group. Intraoperative information delivery to family members in the EPTS and the MBC groups was performed using EPTS and hourly mobile phone contacts, respectively. Data were collected before and after the intervention using the Perceived Stress Scale and the Coping Response Inventory. The SPSS software (v. 22.0) was used for data analysis through the Fisher's exact, Chi-square, independent-sample $t$, and paired-sample $t$ tests.

Results: There were no significant differences between the groups in terms of the pretest and the posttest mean scores of stress and coping ability $(P>0.05)$. The mean scores of stress and coping ability did not significantly change in the EPTS group $(P>0.05)$. Moreover, the mean score of coping ability did not significantly change in the MBC group $(P=0.429)$, while the mean score of stress significantly decreased in this group $(P=0.009)$. Conclusion: Intraoperative information delivery to family members through mobile phone contacts is effective in significantly reducing stress among the family members of patients under CABG. Healthcare providers can use the findings of the present study to provide quality care to patients' family members.

Keywords: Information delivery, Stress, Coping ability, Family
\end{abstract}

*Corresponding Author: Kobra Noorian, Communitybased Nursing Midwifery Research Center, Nursing and Midwifery School, Shahrekord University of Medical Sciences, Shahrekord, Iran.

Email: nooriandehkordy@ yahoo.com

Received: 17 January 2020 Accepted: 11 August 2020 ePublished: 30 March 2021

\section{Introduction}

The prevalence of chronic illnesses such as cardiovascular disease has significantly increased in recent years due to technological advances, urbanization, and unhealthy lifestyle behaviors (1). The World Health Organization reported chronic illnesses as the first leading cause of death throughout the world in 2020 (2). Coronary artery disease is a serious life-threatening cardiovascular disease (3). In the United States, one sixth of all deaths are due to coronary artery disease (4). Cardiovascular disease, particularly coronary artery disease, is also the first leading cause of death in both genders and in all age groups in Iran. A study reported that 166 cases of all 700-800 daily deaths are due to myocardial infarction (5).

The main goal of coronary artery disease management is symptom alleviation and prognosis improvement. Treatments include modification of lifestyle behaviors and management of disease risk factors such as smoking, overweight, and unhealthy eating (6). Despite many advances in the management of coronary artery disease, coronary artery bypass graft (CABG) surgery is still the treatment of choice for most afflicted patients (7).

CABG is a surgical procedure for transplanting a vessel to the obstructed coronary artery in order to bypass blood flow to the cardiac muscle distant to the obstruction (8). The candidates for CABG are patients with triple vessel disease, ejection fraction of less than $30 \%$, obstruction of the left main artery, abnormal anatomy of the coronary arteries, myocardial infarction with no response to treatments, or angina with no response to treatments $(9,10)$. Timely CABG surgery has significant role in reducing the complications of coronary artery disease $(2,11)$.

CABG surgery is a stressful life event and a major threat to health which is associated with senses of fear, anxiety, and tension for afflicted patients and their family members $(12,13)$. Irrespective of the type and the duration of surgery, patient transfer to the operating room (OR) is a stressful experience for family members and is associated with uncertainty and psychological problems

(C) 2021 The Author(s); Published by Shahrekord University of Medical Sciences. This is an open-access article distributed under the terms of the Creative Commons Attribution License (https://creativecommons.org/licenses/by/4.0), which permits unrestricted use, distribution, and reproduction in any medium, provided the original work is properly cited. 
such as stress for them (14). A study reported that stress and anxiety among the family members of the candidates for surgeries are as severe as stress and anxiety among the candidates (15).

The level of stress among family members is at its highest level when their patients are in OR and they are waiting for information about their patients' conditions (16). In this situation, the need for information about patients' conditions, surgical operation, and treatment options is a main need of family members $(17,18)$ and hence, nurses should provide them with adequate support (19). Nurses' appropriate information delivery to family members can improve their coping with their conditions, make their expectations about illness, treatment, and surgery more realistic (20), enable them to use more effective coping strategies, and thereby, reduce their stress. Nonetheless, patients' family members in Iran do not receive adequate and timely information about their patients' conditions (21).

There are different methods for information delivery to the family members of patients in OR. One of these methods is electronic patient tracking system (EPTS), through which patient-related information is presented to family members using a monitor (22). This system can be used to provide family members with appropriate and timely information about their patients in OR (23). Mobile-based communication (MBC) is another method for information delivery to family members. Because of heavy workload and nursing staff shortage, nurses may have limited time for face-to-face communication with patients (24). Therefore, MBC can be used as a simple and easily accessible strategy to provide family members with the opportunity to contact nurses and ask their questions without any need for face-to-face contact (25). Previous studies reported that if used with an at least one-meter distance from medical equipment and devices, $\mathrm{MBC}$ is a safe strategy for communication in healthcare settings $(26,27)$.

EPTS and MBC are used for information delivery to the family members of hospitalized patients in Iran. However, to the best of our knowledge, no study in Iran had yet compared the effects of these strategies. Moreover, previous studies into the effects of these strategies used long-term interventions and hence, there are limited data about the effects of short-term EPTS and MBC interventions. The present study was conducted to narrow these gaps. The aim of the study was to compare the effects of intraoperative information delivery via EPTS and MBC on stress and coping ability among the family members of patients under CABG surgery.

\section{Methods}

This clinical trial was conducted in Kashani hospital, Shahrekord, Iran. Study population consisted of the family members of patients under CABG surgery in the study setting. Participants were selected purposefully. Inclusion criteria were agreement for participation, close kinship relationship with a candidate for nonemergency CABG surgery, active involvement in patient care, an age of eighteen years or more, no history of caregiving to a patient with CABG surgery, ability to speak and comprehend Persian, basic literacy skills, no membership in healthcare delivery teams, no affliction by psychological problems such as stress and anxiety, no hearing or visual impairment, ability to use mobile phone for communication, and presence in OR waiting room throughout CABG surgery. Exclusion criteria were patient death and problems in EPTS or MBC during surgery.

Sample size was calculated with a confidence level of $95 \%$, a power of $80 \%$, and a $d$ of 0.5 . The output of the sample size calculation formula (i.e., $n=\left(z_{1-\alpha / 2}+z_{1-\beta}\right)^{2} / d^{2}$ ) was 31 . Nonetheless, sample size was increased to forty per group in order to compensate probable withdrawals.

Participants were randomly allocated to an EPTS or an MBC group. For randomization, forty cards with E label and forty cards with M label were used. Each eligible participant was asked to randomly select a card. Participants with E-labeled cards were allocated to the EPTS group and participants with M-labeled cards were allocated to the MBC group.

\section{Instruments}

Data collection instruments were a demographic questionnaire, the Perceived Stress Scale, and the Coping Response Inventory. The demographic questionnaire had items on participants' age, gender, educational level, marital status, employment status, history of affliction by health problems, and kinship with patient.

The Perceived Stress Scale was developed in 1983 by Cohen. It has fourteen items on perceived general stress, thoughts and feelings about stressful events, stress control and coping, and perceived stress. Items are scored on a five-point scale as follows: 0: "Never"; 1: "Almost never"; 2: "Sometimes"; 3: "Often"; and 4: "Most of the time". Items $4-7,9,10$, and 13 are reversely scored. The possible total score of the scale is $0-56$ with higher scores showing higher levels of perceived stress (28). Cohen et al. reported that the coefficients of the correlations between the scores of the Perceived Stress Scale and symptomatological measures were $0.52-0.76$ (29). A study in Iran also showed that the Cronbach's alpha of the scale was 0.74 (30). The Coping Response Inventory was developed in 1984. It has 32 items scored on a four-point scale from 0 ("Never") to 3 ("Always"). The possible total score of the inventory is 0-96 (38). The Cronbach's alpha of the Persian Coping Response Inventory was 0.79 (31).

Participants' stress and coping ability were assessed both immediately before patient admission to OR and immediately before patient discharge from OR.

\section{Intervention}

At the time of the study, only one elective CABG surgery was performed per day in the study setting. The candidates for $C A B G$ surgery were hospitalized one day before 
surgery. Therefore, we determined and invited eligible family members to the study the night before the surgery. Information delivery for participants in the EPTS group was performed through the EPTS of the study setting. Accordingly, after OR admission of patients, the names of patients and their surgeons as well as the location of patients in OR (either waiting room, under surgery, or recovery room) were shown for family members using a wall-mounted monitor in family members' waiting room. Participants in the EPTS group had no contact with OR staff during their patients' stay in OR. It is noteworthy that informing family members through EPTS was a routine practice in the study setting and was performed by OR staff. On the other hand, information delivery to participants in the MBC group was performed using mobile phone contacts. Accordingly, after patient admission to OR, OR staff were asked not to show patient information through EPTS. Rather, a mobile phone was provided to his/her main family member and the first author of the study made hourly contacts with the family member and provided him/her with information about surgery progress and patient's conditions. Family members in this group also could make contacts with the first author to receive information about their patients' conditions. As the length of CABG surgery was at least six hours, at least six hourly contacts were made with each participant in the $\mathrm{MBC}$ group. For safety and ethical reasons, the first author made all contacts in the corridor of OR with a distance of at least one meter from OR equipment and devices. The mobile phone used by the first author was in OR throughout the study and was frequently disinfected using alcohol-based disinfectants.

Data analysis was carried out using the SPSS software (v. 22.0). The measures of descriptive statistics (namely absolute frequency, relative frequency, mean, and standard deviation) were used for data description and data normality was tested using the Kolmogorov-Smirnov test. Moreover, the Fisher's exact, chi-square, independentsample $t$, and paired-sample $t$ tests were used for data analysis. The level of significance was set at less than 0.05 .

\section{Results}

All forty participants in each group completed the study (Figure 1). The mean of participants' age was $41.18 \pm 10.83$ years in the MBC and $39.46 \pm 9.74$ years in the EPTS group. Most participants in the MBC and the EPTS groups were female $(68.4 \%$ vs. $53.7 \%)$, married $(81.6 \%$ vs. $78.8 \%)$, and children of patients ( $55.3 \%$ vs. $65.9 \%)$ and most patients were male (57.9\% vs. $63.4 \%)$. Study groups did not significantly differ from each other in terms of participants' characteristics $(P>0.05$; Table 1$)$.

The pretest mean score of stress was $26.00 \pm 7.87$ in the MBC group and $26.34 \pm 6.53$ in the EPTS group with no significant between-group difference $(P=0.834)$. After the study intervention, the mean score of stress was 24.03 \pm 7.91 in the MBC group and $27.07 \pm 6.45$ in the EPTS group and the between-group difference was insignificant $(P=0.064)$. Moreover, the paired-sample $t$ test showed no significant change in the mean score of stress in the EPTS group $(P=0.283)$ and significant decrease in the mean score of stress in the $\mathrm{MBC}$ group $(P=0.009)$. The mean of pretest-posttest change in the score of stress was $-1.97 \pm 4.44$ in the MBC group and $-0.73 \pm 4.30$ in the EPTS group and the between-group difference was statistically significant $(P=0.007)$ (Table 2).

The pretest and the posttest mean scores of coping ability were respectively $45.45 \pm 11.29$ and $44.42 \pm 11.12$ in the MBC group and $44.66 \pm 10.85$ and $45.37 \pm 11.86$ in the EPTS group. There were no significant betweengroup differences respecting the pretest and the posttest mean scores of coping ability $(P>0.05)$. Within-group

Table 1. Between-group comparisons respecting participants' characteristics

\begin{tabular}{|c|c|c|c|c|}
\hline \multirow{2}{*}{ Characteristics } & & \multicolumn{2}{|c|}{ Group } & \multirow[b]{2}{*}{$P$ value } \\
\hline & & MBC & EPTS & \\
\hline \multirow{2}{*}{ Gender } & Male & $12(31.6)$ & $19(46.3)$ & \multirow{2}{*}{0.249} \\
\hline & Female & $26(68.4)$ & $22(53.7)$ & \\
\hline \multirow{5}{*}{ Educational level } & Illiterate & $4(10.5)$ & $5(7.3)$ & \multirow{5}{*}{0.093} \\
\hline & Primary & $0(0)$ & $0(0)$ & \\
\hline & Secondary & $8(21.1)$ & 8 (19.5) & \\
\hline & Diploma & $15(39.5)$ & $26(63.4)$ & \\
\hline & University & $11(29.8)$ & $4(9.8)$ & \\
\hline \multirow{2}{*}{ Employment status } & Employed & $18(47.4)$ & $17(41.5$ & \multirow{2}{*}{0.422} \\
\hline & Unemployed & $17(44.7)$ & $23(56.1)$ & \\
\hline \multirow{2}{*}{ Marital status } & Single & $7(18.4)$ & $5(12.2)$ & \multirow{2}{*}{0.537} \\
\hline & Married & 31 (81.6) & $36(78.8)$ & \\
\hline \multirow{4}{*}{$\begin{array}{l}\text { Kinship with } \\
\text { patient }\end{array}$} & Child & $21(55.3)$ & $27(65.9)$ & \multirow{4}{*}{0.460} \\
\hline & Spouse & $12(31.6)$ & $7(17.1)$ & \\
\hline & Sibling & $2(5.3)$ & $4(9.8)$ & \\
\hline & Other & $3(7.9)$ & $3(7.3)$ & \\
\hline \multirow{2}{*}{ Patient's gender } & Male & $22(57.9)$ & $26(63.4)$ & \multirow{2}{*}{0.651} \\
\hline & Female & $16(42.1)$ & $15(36.6)$ & \\
\hline
\end{tabular}

a The results of the Fisher's exact or the Chi-square test.

Table 2. Between- and within-group comparisons in terms of the mean scores of stress and coping ability

\begin{tabular}{|c|c|c|c|c|}
\hline \multirow{2}{*}{ Variable } & & \multicolumn{2}{|c|}{ Group } & \multirow{2}{*}{$P$ value $^{a}$} \\
\hline & & MBC & EPTS & \\
\hline \multirow{4}{*}{ Stress } & Pretest mean score & $26.00 \pm 7.87$ & $26.34 \pm 6.53$ & 0.834 \\
\hline & Posttest mean score & $24.03 \pm 7.91$ & $27.07 \pm 6.45$ & 0.064 \\
\hline & $P$ value ${ }^{b}$ & 0.009 & 0.283 & - \\
\hline & $\begin{array}{l}\text { Pretest posttest } \\
\text { difference }\end{array}$ & $1.97 \pm 4.44$ & $-0.73 \pm 4.30$ & 0.007 \\
\hline \multirow{4}{*}{$\begin{array}{l}\text { Coping } \\
\text { ability }\end{array}$} & Pretest mean score & $45.45 \pm 11.29$ & $44.66 \pm 10.85$ & 0.752 \\
\hline & Posttest mean score & $44.42 \pm 11.12$ & $45.37 \pm 11.86$ & 0.717 \\
\hline & $P$ value $^{b}$ & 4920. & 0.509 & - \\
\hline & $\begin{array}{l}\text { Pretest posttest } \\
\text { difference }\end{array}$ & $1.03 \pm 9.12$ & $-0.71 \pm 6.79$ & 338.0 \\
\hline
\end{tabular}

${ }^{a}$ The independent-sample $t$ test; ${ }^{\mathrm{b}}$ The paired-sample $t$ test. 


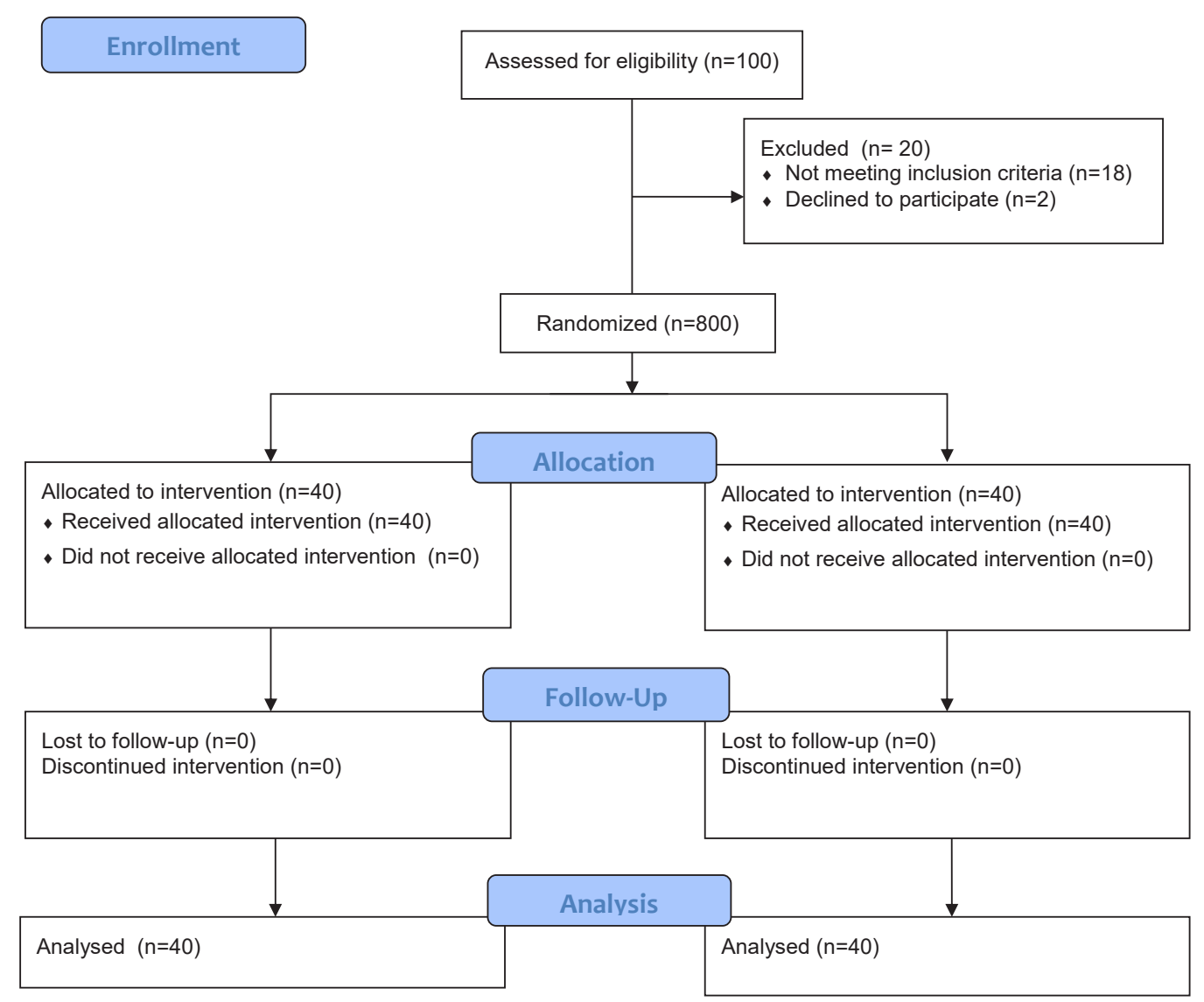

Figure 1. The flow diagram of the study.

comparisons also showed no significant change in the mean score of coping ability in the MBC and the EPTS groups $(P>0.05$; Table 2$)$. The mean of the pretest-posttest change in the score of coping ability was $-1.03 \pm 9.12$ in the MBC group and $0.71 \pm 6.79$ in the EPTS group and the between-group was not statistically significant $(P=0.338)$ (Table 2).

\section{Discussion}

The aim of this study was to compare the effects of intraoperative information delivery via EPTS and MBC on stress and coping ability among the family members of patients under CABG surgery. Most participants were female (68.4\%), married (81.6\%), and children of patients under CABG. Two previous studies in Iran also showed that around half of the family members were the children of patients under CABG $(13,32)$. These findings denote that children are the chief family caregivers of patients under $\mathrm{CABG}$.

Study findings also showed no significant betweengroup differences respecting the pretest and the posttest mean scores of stress, while the mean of pretest-posttest difference in the score of stress in the MBC group was significantly greater than the EPTS group. These findings denote the effectiveness of the MBC intervention and the ineffectiveness of the EPTS intervention in significantly reducing stress among the family members of patients under CABG surgery. A former study assessed the effects of nursing support on depression, anxiety, and stress among the family members of patients under CABG. The intervention of that study included informational, emotional, and personal support. During informational support, family members in that study were provided with information about $\mathrm{CABG}$ and patients' conditions during surgery and their questions were answered in a thirtyminute session. Findings showed significant decrease in the mean score of stress after the study intervention (13) which is in line with the findings of the present study. However, contrary to the present study, the positive effects of the intervention of that study cannot exclusively be attributed to informational support. A qualitative study on nineteen patients under CABG surgery and their family caregivers also showed waiting behind the closed door of OR without receiving adequate information about patient's conditions as the most stressful situation for family caregivers and noted that phone contacts with family caregivers by OR staff helped caregivers better manage their stress (33).

The findings of the present study also showed no significant between- and within-group differences in the mean score of coping ability, denoting that neither MBC nor EPTS had significant effects on coping ability. We found no relevant study for the purpose of comparison. 
What does this paper contribute to the wider global clinical community?

- Family members experience high levels of stress and anxiety during their patient surgery and hence, they should be provided with informational and emotional support as well as the opportunity to ask their questions and express their concerns.

- Hospital managers are recommended to employ strategies for delivering adequate information to the family members of patients under surgery. Such information delivery can be performed through either face-to-face or phone contacts.

\section{Conclusion}

This study concludes that information delivery to family members through mobile phone contacts is effective in significantly reducing psychological stress among the family members of patients under CABG. Healthcare authorities, managers, and providers can use the findings of the present study to provide quality care to these family members. Given the paucity of studies into the effects of information delivery to patients and their family members, further studies in this area are recommended.

\section{Acknowledgement}

This study was part of a Master's thesis in Medical-Surgical Nursing approved and financially supported by the Research and Technology Administration of Shahrekord University of Medical Sciences, Shahrekord, Iran. We would like to sincerely thank the participants of the study and all people who helped us conduct this study.

\section{Ethical Approval}

This study was approved by the Ethics Committee of Shahrekord University of Medical Sciences, Shahrekord, Iran (code: IR.SKUMS.Rcc.154) and registered in the Iranian Registry of Clinical Trials (identifier: IRCT20100511003912N99). Eligible participants received information about the aim and the methods of the study and their informed consent for participation was obtained.

\section{References}

1. Zighaimat F, Ebadi A, Karimi-Zarchi AA, Moradi N, Hajiamini Z, Mehdizadeh S. The effect of education based on health belief model on dietary behavior of coronary artery bypass graft patients. Iran Journal of Nursing. 2010;23(65):50-60. [Persian].

2. Hosseinian A, Kasayi V, Mohammadzade A, Habibzadeh S, Saghi F, Davari M, et al. Evaluation of early complications of coronary artery bypass grafting surgery (CABGS) in the first month after operation in Imam Khomeini hospital of Ardabil during 2013-2014. J Ardabil Univ Med Sci. 2014;14(1):18-27. [Persian].

3. Asgarpour R, Hemmati Maslakpak M, Alinejad V. The effect of needs-based training on the level of the anxiety of families of patients undergoing coronary artery bypass graft surgery. J Urmia Nurs Midwifery Fac. 2016;14(8):665-73. [Persian].

4. Sipahi I, Akay MH, Dagdelen S, Blitz A, Alhan C. Coronary artery bypass grafting vs percutaneous coronary intervention and long-term mortality and morbidity in multivessel disease: meta-analysis of randomized clinical trials of the arterial grafting and stenting era. JAMA Intern Med. 2014;174(2):223-30. doi: 10.1001/jamainternmed.2013.12844.

5. Abbasi Z, Etemadifar S, Javanbakhtian R, Sedehi M. Effect of family centered care on sleep quality of post-CABG patients. J Biochem Tech. 2018;Special issue(2):55-61.

6. Perk J, De Backer G, Gohlke H, Graham I, Reiner $Z$, Verschuren $M$, et al. European Guidelines on cardiovascular disease prevention in clinical practice (version 2012). The Fifth Joint Task Force of the European Society of Cardiology and Other Societies on Cardiovascular Disease Prevention in Clinical Practice (constituted by representatives of nine societies and by invited experts). Eur Heart J. 2012;33(13):1635-701. doi: 10.1093/eurheartj/ehs092.

7. Lewis SM. Lewis's Medical-Surgical Nursing: Assessment and Management of Clinical Problems. Elsevier Australia; 2007.

8. Hinkle JL, Cheever KH. Brunner \& Suddarth's Textbook of Medical-Surgical Nursing. Wolters Kluwer India Pvt Ltd; 2018.

9. Levine GN, Bates ER, Bittl JA, Brindis RG, Fihn SD, Fleisher LA, et al. 2016 ACC/AHA guideline focused update on duration of dual antiplatelet therapy in patients with coronary artery disease: a report of the American College of Cardiology/American Heart Association Task Force on Clinical Practice Guidelines. J Am Coll Cardiol. 2016;68(10):1082-115. doi: 10.1016/j.jacc.2016.03.513.

10. Lopez V, Sek Ying C, Poon CY, Wai Y. Physical, psychological and social recovery patterns after coronary artery bypass graft surgery: a prospective repeated measures questionnaire survey. Int J Nurs Stud. 2007;44(8):1304-15. doi: 10.1016/j. ijnurstu.2006.06.005.

11. Lamy A, Devereaux PJ, Prabhakaran D, Taggart DP, Hu S, Paolasso E, et al. Off-pump or on-pump coronary-artery bypass grafting at 30 days. N Engl J Med. 2012;366(16):1489-97. doi: 10.1056/ NEJMoa1200388.

12. Shoushi F, Jannati Y, Mousavinasab SN, Shafipour V. The impact of family centered care on depression, anxiety and stress of family caregivers of patients undergoing open heart surgery. Iran J Rehabil Res Nurs. 2017;3(2):53-60. [Persian].

13. Zakerimoghadam M, Ghiasvandian S, Salahshoor P. The effect of supportive nursing program on depression, anxiety and stress of family members of patients during coronary artery bypass graft (CABG) surgery. Iran J Cardiovasc Nurs. 2014;3(1):50-8. [Persian].

14. Trimm DR, Sanford JT. The process of family waiting during surgery. J Fam Nurs. 2010;16(4):435-61. doi: 10.1177/1074840710385691.

15. Ghadiri E, Shahriari M, Maghsoudi J. The effects of peer-led education on anxiety of the family caregivers of patients undergoing coronary artery bypass surgery (CABG) in Shahid Chamran center Isfahan University of Medical Sciences. J Nurs Educ. 2016;4(2):50-6. doi: 10.21859/ijpn-04026. [Persian].

16. Hamester L, de Souza EN, Cielo C, Moraes MA, Pellanda LC. Effectiveness of a nursing intervention in decreasing the anxiety levels of family members of patients undergoing cardiac surgery: a randomized clinical trial. Rev Lat Am Enfermagem. 2016;24:e2729. 
doi: 10.1590/1518-8345.0208.2729.

17. Sadeghi T, Dehghan Nayeri N, Abbaszadeh A. The needs of family members in waiting time when their patients undergo surgery: a qualitative study. Payesh. 2016;15(1):41-51. [Persian].

18. Sadeghi T, Dehghan Nayeri N, Abbaszadeh A. Iranian families' experience of receiving support during their patients' surgical process: qualitative study. J Nurs Res. 2014;22(4):268-74. doi: 10.1097/ jnr.0000000000000055.

19. McKiernan M, McCarthy G. Family members' lived experience in the intensive care unit: a phemenological study. Intensive Crit Care Nurs. 2010;26(5):254-61. doi: 10.1016/j.iccn.2010.06.004.

20. Imanipour M, Heidari Z, Seyedfatemi N, Haghani $H$. Effectiveness of informational support on anxiety among family carers of patients undergone open heart surgery. Hayat. 2012;18(3):33-43. [Persian].

21. Najafi $S$, Peyrovi $H$, Haghani $H$. The effect of intraoperative progress report on anxiety of family members of patients under cardiac catheterization. Iran J Cardiovasc Nurs. 2015;3(4):42-9. [Persian].

22. Tariq A, Baysari M, Pedersen $\mathrm{CH}$, Andersen MV, Larsen MM, Shahi M, et al. Examining barriers to healthcare providers' adoption of a hospital-wide electronic patient journey board. Int J Med Inform. 2018;114:1826. doi: 10.1016/j.ijmedinf.2018.03.007.

23. Barberi P. Reducing the Surgical Patient's Family Member's Anxiety Using an Electronic Patient Tracking Board [ dissertation]. Walden University; 2015.

24. Asarrodi A, Heshmatifar N. Assessing barriers toeffective Nurse-patient communication in educational hospitals of Sabzevar. Beyhagh. 2015;19(2):36-46. [Persian].

25. Hanson-Heath CA, Muller LM, Cunningham MF. Evaluating enhancements to a perioperative nurse liaison program. AORN J. 2016;103(4):414-20. doi: 10.1016/j.aorn.2016.01.017.

26. Ettelt S, Nolte E, McKee M, Haugen OA, Karlberg I, Klazinga $N$, et al. Evidence-based policy? the use of mobile phones in hospital. J Public Health (Oxf). 2006;28(4):299-303. doi: 10.1093/pubmed/fdl067.

27. Tri JL, Severson RP, Hyberger LK, Hayes DL. Use of cellular telephones in the hospital environment. Mayo Clin Proc. 2007;82(3):282-5. doi: 10.4065/82.3.282.

28. Durán A, Extremera N, Rey L, Fernández-Berrocal P, Montalbán FM. Predicting academic burnout and engagement in educational settings: assessing the incremental validity of perceived emotional intelligence beyond perceived stress and general selfefficacy. Psicothema. 2006;18 Suppl:158-64.

29. Cohen S, Kamarck T, Mermelstein R. A global measure of perceived stress. J Health Soc Behav. 1983;24(4):38596.

30. Behroozi N, Shahani Yeylaq M, Pourseyed SM. Relationship between perfectionism, perceived stress and social support with academic burnout. Strategy for Culture. 2013;5(20):83-102. [Persian].

31. Hosseini Ghadamgahi J, Dejkam M, Bayanzadeh S, Phaze A. The quality of relationship, stress and coping strategy in patients with coronary heart disease. Iran J Psychiatry Clin Psychol. 1998;4(1):14-25. [Persian].

32. Fallahi Khoshknab M, Farzadmehr M, Hosseini MA, Khankeh HR, NoorAbadi Z. Nursing consultation on anxiety of patient's family in cardiac surgery intensive care unit. J Res Dev Nurs Midwifery. 2016;12(3):1-8. [Persian].

33. Robley L, Ballard N, Holtzman D, Cooper W. The experience of stress for open heart surgery patients and their caregivers. West J Nurs Res. 2010;32(6):794-813. doi: 10.1177/0193945910361469. 